\title{
Nonlaboratory-Based Risk Assessment Algorithm for Undiagnosed Type 2 Diabetes Developed on a Nation-Wide Diabetes Survey
}

XIANGHAI ZHOU, MD, PHD ${ }^{1,2}$

QING QIAO, MD, PHD ${ }^{3,4}$

LINONG JI, MD ${ }^{1,2}$

FENG NING, MS ${ }^{3}$

WENYING YANG, MD ${ }^{5}$

JIANPING WENG, MD ${ }^{6}$

ZHONGYAN SHAN, MD ${ }^{7}$

HAOMING TIAN, MD

OBJECTIVE-To develop a New Chinese Diabetes Risk Score for screening undiagnosed type 2 diabetes in China.

RESEARCH DESICN AND METHODS - Data from the China National Diabetes and Metabolic Disorders Study conducted from June 2007 to May 2008 comprising 16,525 men and 25,284 women aged 20-74 years were analyzed. Undiagnosed type 2 diabetes was detected based on fasting plasma glucose $\geq 7.0 \mathrm{mmol} / \mathrm{L}$ or 2 -h plasma glucose $\geq 11.1 \mathrm{mmol} / \mathrm{L}$ in people without a prior history of diabetes. $\beta$-Coefficients derived from a multiple logistic regression model predicting the presence of undiagnosed type 2 diabetes were used to calculate the New Chinese Diabetes Risk Score. The performance of the New Chinese Diabetes Risk Score was externally validated in two studies in Qingdao: one is prospective with follow-up from 2006 to 2009 (validation 1) and another cross-sectional conducted in 2009 (validation 2).

RESULTS-The New Chinese Diabetes Risk Score includes age, sex, waist circumference, BMI, systolic blood pressure, and family history of diabetes. The score ranges from 0 to 51 . The area under the receiver operating curve of the score for undiagnosed type 2 diabetes was 0.748 $(0.739-0.756)$ in the exploratory population, $0.725(0.683-0.767)$ in validation 1 , and 0.702 (0.680-0.724) in validation 2 . At the optimal cutoff value of 25 , the sensitivity and specificity of the score for predicting undiagnosed type 2 diabetes were 92.3 and $35.5 \%$, respectively, in validation 1 and 86.8 and $38.8 \%$ in validation 2 .

CONCLUSIONS - The New Chinese Diabetes Risk Score based on nonlaboratory data appears to be a reliable screening tool to detect undiagnosed type 2 diabetes in Chinese population.

Diabetes Care 36:3944-3952, 2013

\footnotetext{
From the ${ }^{1}$ Department of Endocrinology and Metabolism, Peking University People's Hospital, Beijing, China; the ${ }^{2}$ Peking University Diabetes Center, Beijing, China; the ${ }^{3}$ Department of Public Health, University of Helsinki, Helsinki, Finland; the ${ }^{4}$ Diabetes Prevention Unit, Department of Chronic Disease Prevention, National Institute for Health and Welfare, Helsinki, Finland; the ${ }^{5}$ China-Japan Friendship Hospital, Beijing, China; the ${ }^{6}$ Sun Yat-sen University Third Hospital, Guangzhou, China; the ${ }^{7}$ First Affiliated Hospital, Chinese Medical University, Shenyang, China; the ${ }^{8}$ West China Hospital, Sichuan University, Chengdu, China; the ${ }^{9}$ Xijing Hospital, Fourth Military Medical University, Xi'an, China; the ${ }^{10}$ Fujian Provincial Hospital, Fuzhou, China; ${ }^{11}$ The Second Affiliated Hospital of Harbin Medical University, Harbin, China; and the ${ }^{12}$ Qingdao Municipal Centers for Disease Control and Prevention, Qingdao, China.

Corresponding author: Linong Ji, jiln@bjmu.edu.cn.

Received 11 March 2013 and accepted 9 July 2013.

DOI: $10.2337 / \mathrm{dcl} 3-0593$

This article contains Supplementary Data online at http://care.diabetesjournals.org/lookup/suppl/doi:10 .2337/dc13-0593/-/DC1.

(C) 2013 by the American Diabetes Association. Readers may use this article as long as the work is properly cited, the use is educational and not for profit, and the work is not altered. See http://creativecommons.org/ licenses/by-nc-nd/3.0/ for details.
}

Devalence of type 2 diabetes is increasing dramatically worldwide. In China, the prevalence of type 2 diabetes increased from $5.5 \%$ in 2000 2001 (1) to $9.7 \%$ in $2007-2008$ (2). Nearly $60 \%$ of individuals with type 2 diabetes had not been diagnosed previously (2). Mortality in individuals with previously undiagnosed type 2 diabetes was, however, as high as in those with known type 2 diabetes; both were higher than in people without type 2 diabetes (3). Obesity, hypertension, and dyslipidemia are also frequently clustered in an individual with undiagnosed type 2 diabetes $(2,4,5)$. Early detection of type 2 diabetes and intervention may reduce exposure to longterm hyperglycemia and prevent or delay chronic diabetes complications. The currently used diagnostic tool for type 2 diabetes is 75 -g oral glucose tolerance test (OGTT) and AlC (6). The OGTT is, however, time consuming, and the fasting status cannot be assured. The AlC test is less standard and relatively expensive. Consequently, their use in mass screening has been limited. Risk score developed based on demographic, anthropometric, and clinical information without a laboratory test has been proved to be a useful and cheap tool for a stepwise screening strategy for undiagnosed type 2 diabetes (7-17). This approach is particularly useful in China, considering a large population and an already high and still increasing prevalence of undiagnosed type 2 diabetes.

A simple Chinese diabetes risk score has been reported based on data collected in Qingdao (7). Considering the diversity in economic development, culture, living environment, and dietary factors in different areas of China, we tried to develop a New Chinese Diabetes Risk Score for undiagnosed type 2 diabetes using the data of the China National Diabetes and Metabolic Disorders Study (exploratory population) that was conducted in 12 provinces and autonomous regions in addition to the municipalities of Beijing and Shanghai from June 2007 to May 2008. 
The performance of the New Chinese Diabetes Risk Score developed in this study is validated in two external studies in Qingdao. One of the two studies is prospective (validation 1) and the other crosssectional (validation 2 ). The results of the validation of the indexed score are also compared with previously published diabetes risk scores that derived from Chinese (7), Caucasian $(9,11,13,14,18)$, and other Asian populations $(15,16,19,20)$.

\section{RESEARCH DESIGN AND METHODS}

\section{Population for development of the New Chinese Diabetes Risk Score (exploratory population)}

The China National Diabetes and Metabolic Disorders Study was a cross-sectional study conducted from June 2007 to May 2008. The study population and the methods used to recruit participants have previously been reported (2). In brief, a multistage, stratified sampling method was used to recruit a population-representative sample of individuals aged $\geq 20$ years who lived in their current residence for at least 5 years. The study was conducted in a total of 152 urban street districts and 112 rural villages selected from 12 provinces and autonomous regions in addition to the municipalities of Beijing and Shanghai. A total of 54,240 individuals were invited to participate in the study, and 47,325 attended, which give a response rate of $87.3 \%$. A total of 41,809 participants aged 20-74 years were included in the current data analyses after exclusion of 2,151 individuals with previously diagnosed diabetes, 343 aged $\geq 75$ years, and 2,785 with missing data on demographic information, fasting or 2-h blood glucose levels, waist circumference, BMI, systolic blood pressure or diastolic blood pressure, family history of diabetes, or information on education. To minimize the influence of extreme values, we further excluded 69 individuals with waist circumference $>99.9$ percentile $(120 \mathrm{~cm})$ or $<0.1$ percentile $(56 \mathrm{~cm}), 71$ individuals with BMI $>99.9$ percentile $\left(39.74 \mathrm{~kg} / \mathrm{m}^{2}\right)$ or $<0.1$ percentile $\left(15.23 \mathrm{~kg} / \mathrm{m}^{2}\right), 53$ individuals with systolic blood pressure $>99.9$ percentile $(205 \mathrm{mmHg})$ or $<0.1$ percentile $(80 \mathrm{mmHg}$ ), and 44 individuals with diastolic blood pressure $>99.9$ percentile $(125 \mathrm{mmHg})$ or $<0.1$ percentile $(50$ $\mathrm{mmHg}$ ). The survey was approved by the institutional review board or local ethics committee, and informed consent was obtained from all participants.
Population for external validation of the New Chinese Diabetes Risk Score (validation population)

Qingdao prospective diabetes survey from 2006 to 2009 (validation 1). A population-based cross-sectional diabetes survey was conducted in three urban and three rural administrative areas in Qingdao, China in 2006 (21). A stratified, random cluster sampling method was used to recruit a representative sample of the general population who had lived in Qingdao city for at least 5 years. A total of 5,355 individuals aged 35-74 years attended the 2006 cross-sectional diabetes survey. In $2009,4,482$ of the 5,355 participants who did not have diabetes at baseline were invited to join a follow-up to determine the incident cases of type 2 diabetes, and 1,294 attended. Data from 1,162 of the 1,294 participants who had all variables required for the validation study were used to validate the risk scores.

Qingdao cross-sectional diabetes survey 2009 (validation 2). A populationbased cross-sectional diabetes survey was conducted in Qingdao, China, in 2009. The survey used the same sampling method and was conducted in the same areas as the 2006 survey above. A total of 7,612 individuals aged 35-74 years were invited to participate in the survey, and 5,110 attended, which gave a response rate of $67.1 \%$. We validated the risk scores in 4,274 participants who had completed data required. Both surveys were approved by the Qingdao Municipal Health Bureau and the local ethics committee in the Qingdao Municipal Centers for Disease Control and Prevention, and informed consent was obtained from all participants.

In the exploratory, validation 1 , and validation 2 population, participants were interviewed by trained doctors or nurses in the local community clinics. Residence area was divided into rural area and urban area including urban and suburban area. Educational level was divided into college or higher level and others including secondary school and elementary school or illiterate. Smoking status was classified as current smoker if smoking at least one cigarette daily and other including nonsmokers and ex-smokers. Physical activity was defined as participation in moderate or vigorous activity for at least 90 min or more per week. Hypertension was defined as self-report of hypertension diagnosed by a doctor or on antihypertensive treatment or defined by systolic blood pressure $\geq 140 \mathrm{mmHg}$ or diastolic blood pressure $\geq 90 \mathrm{mmHg}$ based on the mean of the two measures for each individual in the exploratory population and three measures in validation 1 and validation 2 . Diabetes in a first-degree relative (parents, siblings, and offspring) was considered a family history of diabetes.

Height and weight were measured using a height-weight scale that had been calibrated before using and with subjects standing with bare feet and light clothing. Waist circumference was measured at the middle point level between lower rib margin and iliac crest. Waist circumference was divided into six categories in men and women: $<75, \geq 75$ and $<80, \geq 80$ and $<85, \geq 85$ and $<90, \geq 90$ and $<95$, and $\geq 95 \mathrm{~cm}$ in men and $<70$, $\geq 70$ and $<75, \geq 75$ and $<80, \geq 80$ and $<85, \geq 85$ and $<90$, and $\geq 90 \mathrm{~cm}$ in women. BMI was calculated as weight in kilograms divided by the square of height in meters and divided into four categories: $<22, \geq 22$ and $<24, \geq 24$ and $<30$, and $\geq 30 \mathrm{~kg} / \mathrm{m}^{2}$. Systolic blood pressure was divided into seven categories: $<110$, $\geq 110$ and $<120, \geq 120$ and $<130, \geq 130$ and $<140, \geq 140$ and $<150, \geq 150$ and $<160$, and $\geq 160 \mathrm{mmHg}$.

The study participants were instructed to maintain their usual physical activity and have at least 3 days of unrestricted diet ( $\geq 150 \mathrm{~g}$ carbohydrate/day) and an overnight fast of at least $10 \mathrm{~h}$ before examination. OGTT was performed in the morning. Blood samples were collected before glucose ingestion and $2 \mathrm{~h}$ after a 75-g anhydrous glucose load. Plasma glucose (PG) was measured by the hexokinase enzymatic method in the exploratory population and the glucose oxidase method in the validation 1 and validation 2 population.

Known diabetes was defined as selfreport of diabetes diagnosed by a doctor or on information on treatment, and individuals with known diabetes were excluded from the analysis. According to the World Health Organization definition (22), previously undiagnosed type 2 diabetes was defined as having either fasting plasma glucose $(\mathrm{FPG}) \geq 7.0 \mathrm{mmol} / \mathrm{L}$ or 2 -h PG $\geq 11.1 \mathrm{mmol} / \mathrm{L}$. Nondiabetes was defined as FPG $<7.0 \mathrm{mmol} / \mathrm{L}$ and 2-h PG $<11.1 \mathrm{mmol} / \mathrm{L}$.

The exploratory population was comprised of more women than men because more women participated in the China National Diabetes and Metabolic Disorders Study. In addition, the exploratory population was younger than the two 
validation populations. To check the possible impact of the imbalance in sex and age, we performed two sensitivity analyses. First, a risk score was derived for men and women separately. Second, a risk score was derived for the exploratory population by limiting the age to 35-74 years. The results of the two sensitivity analyses were compared, with the main results reported in the current article.

\section{Statistical analysis}

Statistical analysis was performed using SPSS for Windows, version 15.0 (SPSS, Chicago, IL) and STATA, version 11.2 (StataCorp, College Station, TX). Continuous variables are presented as means $\pm \mathrm{SD}$ and categorical data as number and percentage. A multivariable logistic regression model using the forward stepwise likelihood ratio method was fitted with candidate risk factors including age, sex, BMI, waist circumference, systolic blood pressure, family history of diabetes, educational level, and residence. All of the candidate risk factors were categorized. The New Chinese Diabetes Risk Score was derived by multiplying the $\beta$-coefficients of the significant variable by 10 and rounding to the nearest integer. The Hosmer-Lemeshow test was used to investigate how close the prevalence predicted by the multivariate model was to the observed prevalence. The difference was considered nonsignificant at $P>0.05$. We classified the predicted probabilities of having diabetes according to its quartiles ( $\leq 2.4 \%$, $>2.4 \%$ and $\leq 4.9 \%,>4.9 \%$ and $\leq 9.4 \%$, and $>9.4 \%$ ) based on a multivariable model fitted with age, sex, waist circumference, and family history of diabetes that were the components of the Qingdao Chinese diabetes risk score (7). Net reclassification improvement (23) was calculated to test whether adding BMI and systolic blood pressure could improve the classification of the predicted probabilities of the multivariable model.

Validation of the New Chinese Diabetes Risk Score developed from the exploratory population was conducted in the validation 1 and validation 2 population. The receiver operating characteristic (ROC) curve was obtained by plotting sensitivity against $1-$ specificity at each cutoff value. The optimal cutoff point was identified using the Youden index, which was at the maximum sum of the sensitivity and specificity -1 . Diagnostic accuracy was assessed by the area under the curve (AUC) (24). C statistics were used to compare the AUCs.
RESULTS-The exploratory population was younger and less hypertensive and had a lower proportion of undiagnosed type 2 diabetes and a higher proportion of urban living compared with validation 1 and validation 2 . The exploratory population and validation 2 population were less obese and had a lower proportion of family history of diabetes compared with the validation 1 population (Table 1). A total of 3,365 (7.4\%) individuals who participated in the China National Diabetes and Metabolic Disorders Study and had no prior history of diagnosis of diabetes were excluded from the current data analyses because of age $\geq 75$ years, missing variables, or extreme values. They were older (age 49.4 years [95 CI 48.9-49.9] vs. 44.1 years [44.0-44.2]), had a higher proportion of men (44.9 vs. $39.5 \%, P<$ $0.001)$, higher BMI $\left(24.6 \mathrm{~kg} / \mathrm{m}^{2}[95 \%\right.$ CI 24.4-24.7] vs. $24.0 \mathrm{~kg} / \mathrm{m}^{2}$ [24.024.1]), and higher systolic blood pressure (124.6 mmHg [95\% CI 123.9-125.2] vs. $121.8 \mathrm{mmHg}$ [121.6-122.0]) but lower FPG $(5.19 \mathrm{mmol} / \mathrm{L}$ [95\% CI 5.15-5.23] vs. $5.24 \mathrm{mmol} / \mathrm{L}$ [5.23-5.25] as compared with those included in the current data analysis. Of 4,482 participants in the 2006 Qingdao Diabetes Survey, 1,294 attended the follow-up survey in 2009. Participants did not differ much from nonparticipants in age (49.3 years [95\% CI 48.8-49.8] vs. 48.9 years [48.649.3]), FPG (5.37 mmol/L [95\% CI $5.33-5.41]$ vs. $5.41 \mathrm{mmol} / \mathrm{L}[5.39-$ 5.44]), 2-h PG (6.50 mmol/L [95\% CI

Table 1-Baseline characteristics of participants in the China National Diabetes and Metabolic Disorders Study (exploratory population), Qingdao prospective study 2006-2009 (validation 1), and Qingdao cross-sectional survey 2009 (validation 2)

\begin{tabular}{|c|c|c|c|}
\hline & $\begin{array}{l}\text { Exploratory } \\
\text { population }\end{array}$ & Validation $1^{*}$ & Validation 2 \\
\hline \multicolumn{4}{|l|}{ Men } \\
\hline N & 16,525 & 405 & 1,693 \\
\hline Age (years) & $44 \pm 14$ & $50 \pm 10$ & $52 \pm 11$ \\
\hline BMI $\left(\mathrm{kg} / \mathrm{m}^{2}\right)$ & $24.4 \pm 3.6$ & $25.7 \pm 3.3$ & $24.4 \pm 3.8$ \\
\hline Waist circumference $(\mathrm{cm})$ & $85.1 \pm 10.3$ & $87.1 \pm 9.6$ & $84.1 \pm 12.2$ \\
\hline Systolic blood pressure $(\mathrm{mmHg})$ & $124 \pm 18$ & $135 \pm 20$ & $134 \pm 21$ \\
\hline Diastolic blood pressure (mmHg) & $80 \pm 11$ & $88 \pm 12$ & $83 \pm 13$ \\
\hline Family history of diabetes & 1,961 (11.9) & $63(15.6)$ & $142(8.4)$ \\
\hline Current smoker & $7,981(48.3) \dagger$ & $193(47.7)$ & $1,016(60.1) \dagger$ \\
\hline Urban living & $10,141(61.4)$ & $108(26.7)$ & $279(16.5)$ \\
\hline Less than college education & $12,039(72.9)$ & $356(87.9)$ & $1,611(95.4) \dagger$ \\
\hline Regular leisure-time physical activity & $6,083(36.9) \dagger$ & $71(17.8) \dagger$ & $301(17.8)$ \\
\hline Undiagnosed diabetes & $1,241(7.5)$ & $62(15.3) \ddagger$ & $242(14.3)$ \\
\hline FPG $(\mathrm{mmol} / \mathrm{L})$ & $5.3 \pm 1.1$ & $6.0 \pm 1.1 \neq$ & $5.9 \pm 1.3$ \\
\hline 2-h PG (mmol/L) & $6.6 \pm 2.8$ & $7.3 \pm 2.8 \dagger+$ & $7.1 \pm 3.1 \dagger$ \\
\hline Triglycerides (mmol/L) & $1.4(1.0-2.0) \dagger$ & $1.1(0.8-1.6) \dagger$ & $1.1(0.8-1.7)$ \\
\hline \multicolumn{4}{|l|}{ Women } \\
\hline N & 25,284 & 757 & 2,581 \\
\hline Age (years) & $44 \pm 13$ & $48 \pm 9$ & $51 \pm 10$ \\
\hline BMI $\left(\mathrm{kg} / \mathrm{m}^{2}\right)$ & $23.8 \pm 3.6$ & $26.0 \pm 3.6$ & $25.3 \pm 3.9$ \\
\hline Waist circumference $(\mathrm{cm})$ & $79.0 \pm 9.9$ & $81.9 \pm 9.3$ & $82.4 \pm 11.6$ \\
\hline Systolic blood pressure $(\mathrm{mmHg})$ & $120 \pm 19$ & $133 \pm 22$ & $133 \pm 23$ \\
\hline Diastolic blood pressure $(\mathrm{mmHg})$ & $77 \pm 11$ & $84 \pm 11$ & $82 \pm 12$ \\
\hline Family history of diabetes & 3,341 (13.2) & $130(17.2)$ & $253(9.8)$ \\
\hline Current smoker & $685(2.7) \dagger$ & $15(2.0)$ & $105(4.2) \dagger$ \\
\hline Urban living & $16,399(64.9)$ & $205(27.1)$ & $657(25.5)$ \\
\hline Less than college education & 20,069 (79.4) & $708(93.5)$ & $2,499(96.9) \dagger$ \\
\hline Regular leisure-time physical activity & $9,083(36.0) \dagger$ & $113(15.2) \dagger$ & $404(15.7)$ \\
\hline Undiagnosed diabetes & $1,479(5.8)$ & $80(10.6) \ddagger$ & $302(11.7)$ \\
\hline FPG $(\mathrm{mmol} / \mathrm{L})$ & $5.2 \pm 1.1$ & $5.7 \pm 0.8 \ddagger$ & $5.7 \pm 1.1$ \\
\hline 2-h PG (mmol/L) & $6.6 \pm 2.7$ & $7.4 \pm 2.3+\$$ & $7.3 \pm 2.6 \dagger$ \\
\hline Triglycerides (mmol/L) & $1.2(0.8-1.7) \dagger$ & $0.9(0.7-1.4) \dagger$ & $1.2(0.8-1.7)$ \\
\hline
\end{tabular}

Data are mean $\pm \mathrm{SD}, n(\%)$, or median (25th-75th percentile) unless otherwise indicated. *Baseline characteristics unless otherwise indicated. †With missing data. †Follow-up data. 
6.40-6.59] vs. $6.47 \mathrm{mmol} / \mathrm{L}$ [6.41$6.53])$, or family history of diabetes (16.9 vs. $17.0 \%, P=0.923$ ), but the participants in the follow-up study had slightly higher BMI $\left(25.9 \mathrm{~kg} / \mathrm{m}^{2}\right.$ [95\% CI 25.7-26.1] vs. $25.4 \mathrm{~kg} / \mathrm{m}^{2}$ [25.3-25.5]) and higher systolic blood pressure (133.3 mmHg [95\% CI 132.3-134.4] vs. 130.7 mmHg [130.0-131.4]) but a lower proportion of men (34.3 vs. 39.3\%, $P=0.002)$.

In the multivariable logistic regression analysis, increased age, male sex, BMI, waist circumference, systolic blood pressure, and positive family history of diabetes in a first-degree relative were significantly associated with the presence of undiagnosed type 2 diabetes (Table 2). The Hosmer-Lemeshow test showed that the predicted prevalence of undiagnosed type 2 diabetes of the multivariable model matched well with the observed prevalence $\left(\chi^{2}=6.99, P=0.537\right)$. Addition of BMI and systolic blood pressure into the multivariable model fitted with age, sex, waist circumference, and family history of diabetes improved the reclassification of the predicted probabilities of the model (net reclassification improvement $=0.048$, $P<0.001$ ).

The risk score was developed based on the multivariable model (Table 2). The point totals ranged from 0 to 51 . The optimal cutoff point for previously

Table 2-Odds ratio (95\% CI) and $\boldsymbol{\beta}$-coefficient for prevalence of previously undiagnosed diabetes in the 41,809 participants of the exploratory population, estimated using logistic regression analysis

B-Coefficient $\quad$ OR $(95 \% \mathrm{CI}) \quad$ Score

\begin{tabular}{|c|c|c|c|}
\hline \multicolumn{4}{|l|}{ Age (years) } \\
\hline $20-24$ & - & 1.00 & 0 \\
\hline $25-34$ & 0.393 & $1.48(1.04-2.11)$ & 4 \\
\hline $35-39$ & 0.780 & $2.18(1.54-3.10)$ & 8 \\
\hline $40-44$ & 1.052 & $2.86(2.03-4.04)$ & 11 \\
\hline $45-49$ & 1.228 & $3.41(2.42-4.80)$ & 12 \\
\hline $50-54$ & 1.292 & $3.64(2.59-5.12)$ & 13 \\
\hline $55-59$ & 1.515 & $4.55(3.23-6.41)$ & 15 \\
\hline $60-64$ & 1.648 & $5.20(3.67-7.36)$ & 16 \\
\hline $65-74$ & 1.814 & $6.14(4.36-8.64)$ & 18 \\
\hline \multicolumn{4}{|l|}{ BMI $\left(\mathrm{kg} / \mathrm{m}^{2}\right)$} \\
\hline$<22$ & - & 1.00 & 0 \\
\hline $22-23.9$ & 0.122 & $1.13(0.97-1.32)$ & 1 \\
\hline $24-29.9$ & 0.266 & $1.30(1.12-1.52)$ & 3 \\
\hline$\geq 30$ & 0.544 & $1.72(1.41-2.11)$ & 5 \\
\hline \multicolumn{4}{|l|}{ Waist circumference (cm) } \\
\hline$<75$ (men) or $<70$ (women) & - & 1.00 & 0 \\
\hline 75-79.9 (men) or 70-74.9 (women) & 0.280 & $1.32(1.05-1.66)$ & 3 \\
\hline 80-84.9 (men) or 75-79.9 (women) & 0.536 & $1.71(1.37-2.13)$ & 5 \\
\hline 85-89.9 (men) or 80-84.9 (women) & 0.660 & $1.94(1.55-2.42)$ & 7 \\
\hline 90-94.9 (men) or 85-89.9 (women) & 0.847 & $2.33(1.85-2.94)$ & 8 \\
\hline$\geq 95$ (men) or $\geq 90$ (women) & 1.028 & $2.79(2.22-3.52)$ & 10 \\
\hline \multicolumn{4}{|l|}{ Systolic blood pressure (mmHg) } \\
\hline$<110$ & - & 1.00 & 0 \\
\hline $110-119$ & 0.149 & $1.16(0.98-1.37)$ & 1 \\
\hline $120-129$ & 0.346 & $1.41(1.21-1.65)$ & 3 \\
\hline $130-139$ & 0.618 & $1.85(1.58-2.18)$ & 6 \\
\hline $140-149$ & 0.725 & $2.07(1.74-2.46)$ & 7 \\
\hline $150-159$ & 0.786 & $2.19(1.80-2.67)$ & 8 \\
\hline$\geq 160$ & 1.006 & $2.73(2.27-3.29)$ & 10 \\
\hline \multicolumn{4}{|l|}{ Family history of diabetes, yes vs. no } \\
\hline No & - & 1.00 & 0 \\
\hline Yes & 0.623 & $1.86(1.68-2.06)$ & 6 \\
\hline \multicolumn{4}{|l|}{ Sex } \\
\hline Women & - & 1.00 & 0 \\
\hline Men & 0.217 & $1.24(1.15-1.35)$ & 2 \\
\hline
\end{tabular}

undiagnosed diabetes was 25. A total of 17,704 (42.3\%) participants in the exploratory population had a risk score $\geq 25$, and 2,097 (11.8\%) had diabetes. The AUCs of the ROC curve were 0.748 (95\% CI 0.739-0.756) in the exploratory population.

The AUCs of the New Chinese Diabetes Risk Score for predicting incidence of type 2 diabetes based on validation 1 were 0.725 (955 CI 0.683-0.767), 0.635 (0.566-0.705), and 0.770 (0.715-0.824) in all individuals, men, and women; they were $0.702(0.680-0.724), 0.678$ (0.643-0.713), and 0.717 (0.688$0.747)$, respectively, for detecting the prevalence of undiagnosed type 2 diabetes based on validation 2. A total of 789 (67.9\%) individuals in validation 1 and $2,754(64.4 \%)$ in validation 2 had a risk score $\geq 25$ points. At the cutoff point $\geq 25$, the sensitivity and specificity were 92.3 and $35.5 \%$ in validation 1 and 86.8 and $38.8 \%$ in validation 2 , respectively. At a cutoff point $\geq 30$, moderate sensitivity (75.4\% in validation 1 and $67.8 \%$ in validation 2 ) and specificity (57.8\% in validation 1 and $61.2 \%$ in validation 2 ) were achieved.

In the sensitivity analysis separately for men and women, age, BMI, waist circumference, systolic blood pressure, and family history of diabetes remained in the final model in both sexes. Urban living was an additional risk factor for men. The AUC for men (0.731 [0.718$0.745]$ vs. $0.729[0.716-0.743])$ and women $(0.758$ [0.746-0.770] vs. 0.757 [0.745-0.769]) was not different from that derived from the model combining both men and women in the exploratory population. The second sensitivity analysis by limiting the age of the exploratory population to 35-74 years was performed among 11,941 men and 18,918 women; mean (SD) age of both was 50 (10) years. The risk-assessment algorithm derived from the second sensitivity analysis comprised basically the same risk factors as the New Chinese Diabetes Risk Score except for an additional variable of the educational level, and both performed equally well regarding the AUC in the validation databases (AUC 0.725 [0.6830.767 ] in validation 1 and 0.701 [0.6790.724 ] in validation 2).

Discrimination of the New Chinese Diabetes Risk Score was compared with 10 scores derived from other populations that were applicable to validation 1 and validation 2 (Table 3 and Fig. 1). The performance of the New Chinese Diabetes 
Risk score for type 2 diabetes

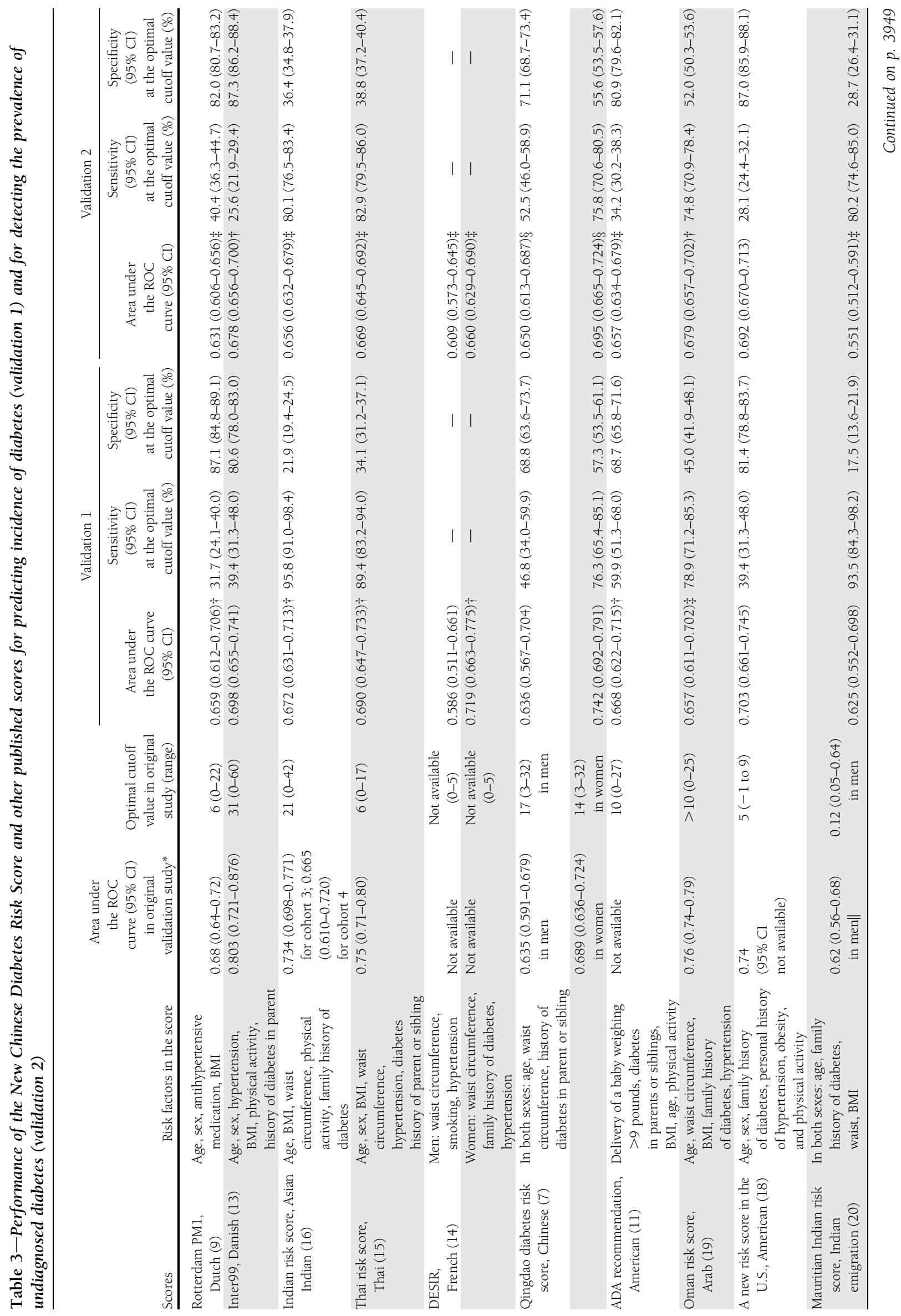


Score is superior to other existing risk scores in terms of AUCs.

CONCLUsIONS-The New Chinese Diabetes Risk Score for detecting undiagnosed type 2 diabetes comprising of age, sex, waist circumference, BMI, family history of diabetes, and systolic blood pressure was developed based on data of the China National Diabetes and Metabolic Disorders Study. The performance of the New Chinese Diabetes Risk Score is adequate regarding the detecting and predicting type 2 diabetes in the Chinese population and performs better than most of the existing risk scores for detecting undiagnosed type 2 diabetes in the validation population of the Qingdao cross-sectional survey in 2009.

Several risk scores for predicting $(12,14,15,17)$ or detecting $(7-11,13,16$, 25) undiagnosed type 2 diabetes have been developed; most of these were derived from Caucasian populations (8-14) and a few from Asian populations $(7,15-17,25)$. The common risk factors involved in the scores were age, family history of diabetes, and anthropometric indicators of obesity. The AUCs of these existing risk scores for type 2 diabetes ranged from 0.62 to 0.80 in the original population. Most of these existing risk scores performed better in their original population than in the two Chinese validation populations, indicating that a raceor country-specific risk score may be needed. Compared with another Chinese risk score derived from Chinese living in Qingdao (7), two more risk factors including BMI and systolic blood pressure were added to the new risk score we developed, which improved the performance of the prediction significantly. Blood pressure is usually measured by health care providers during a clinic visit or periodic health check-up in China. The New Chinese Diabetes Risk Score can be introduced to the health care providers or added to a check-up program to increase the chance for type 2 diabetes screening in health care settings. For people who can measure blood pressure at home, the risk score can also be applied to lay populations. Because a blood pressure monitor is not available in most families in China as well as in some remote areas with scarce medical resources, the Qingdao diabetes risk score can be applied to the families and regions where blood pressure measure is not available.

The strength of the current score is that it is developed based on data of the 
A

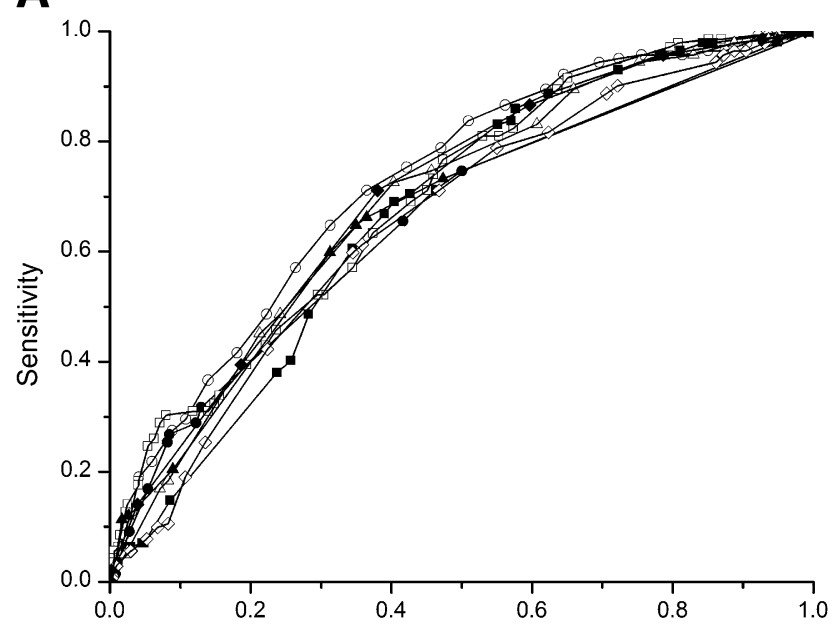

B

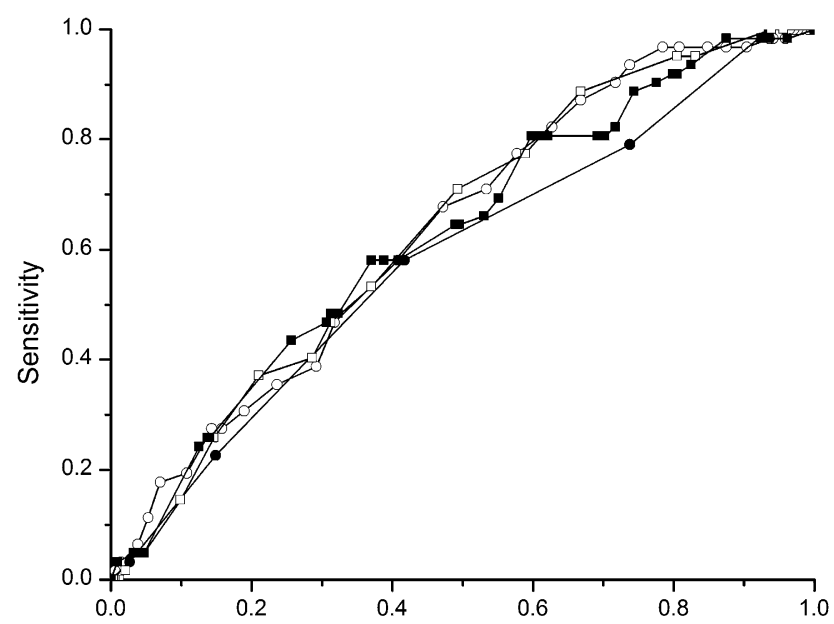

C

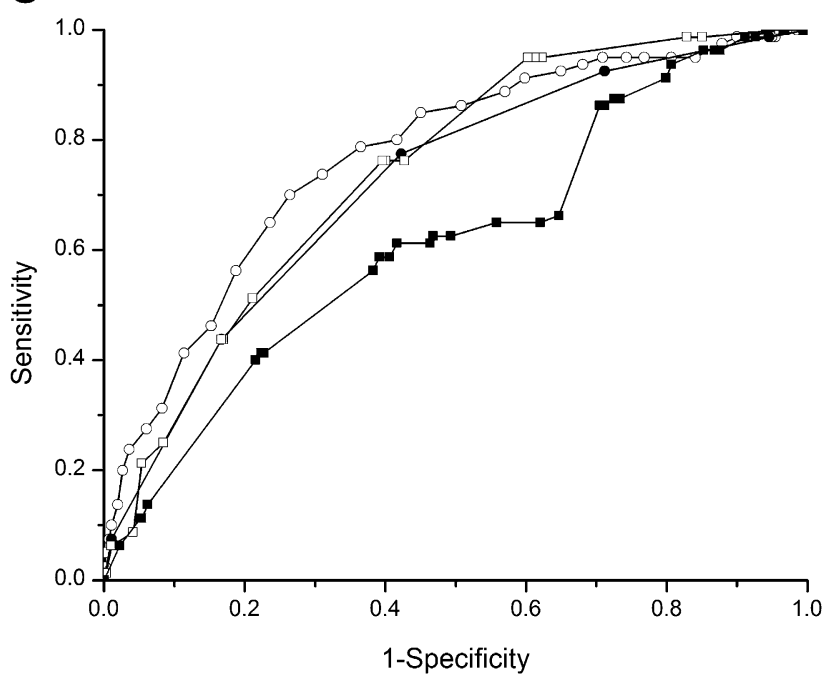

D

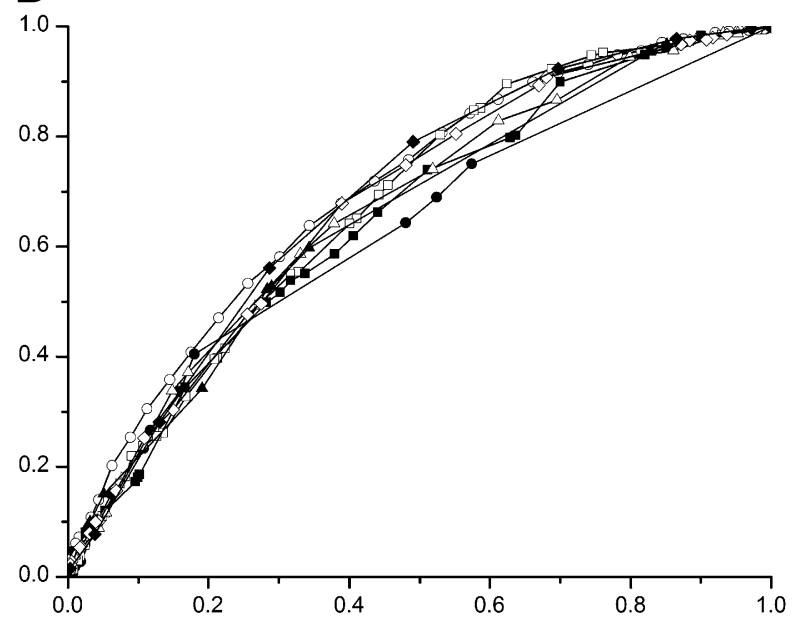

E

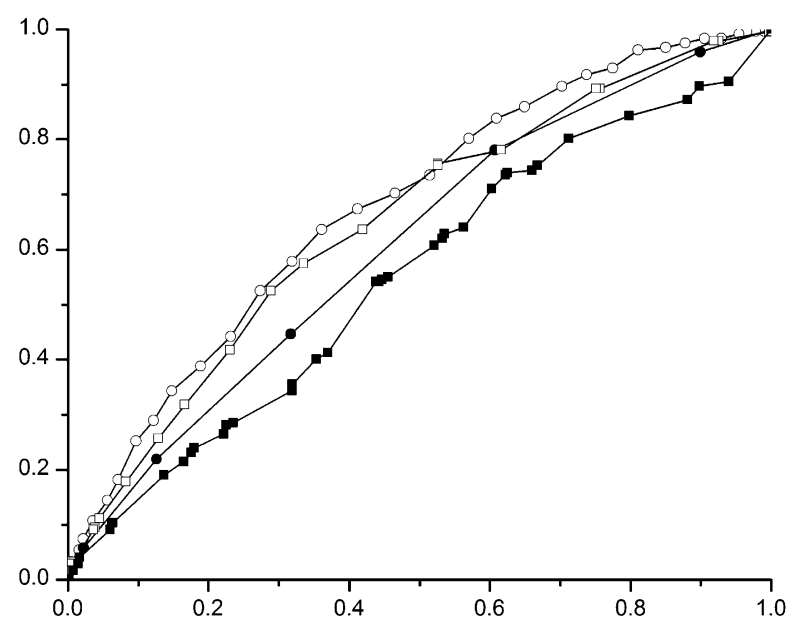

$\mathbf{F}$

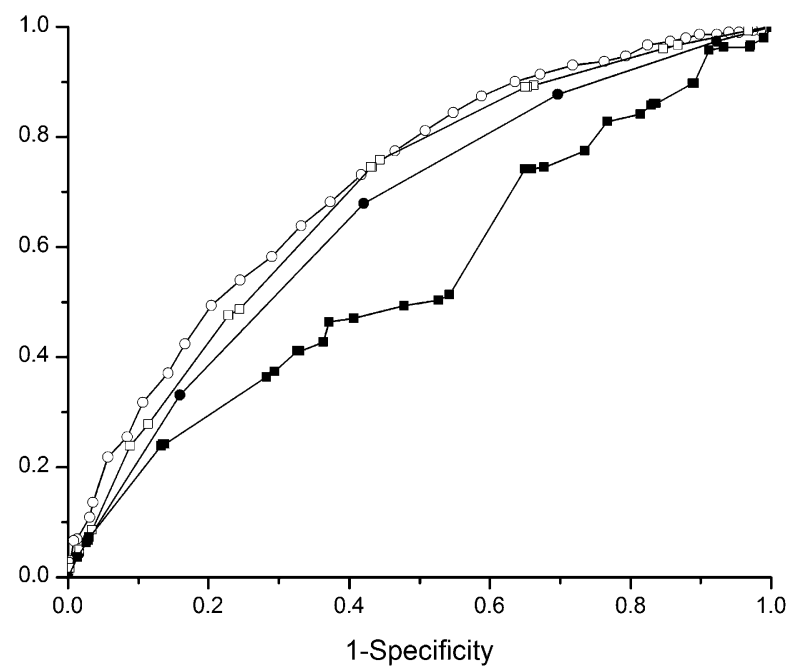

Figure 1-Performance of various risk scores for predicting incidence of diabetes (A-C) and detecting prevalence of undiagnosed diabetes (D-F) based on external validation. A: Validation 1. B: Men in validation 1. C: Women in validation 1. D: Validation 2. E: Men in validation 2. F: Women in validation 2. A and D: $\bigcirc$, the New Chinese Diabetes Risk Score; $\bigcirc$, Rotterdam PM1; $\square$, Inter99; $\mathbf{\square}$, Indian risk score; $\triangle$, Thai risk score; $\boldsymbol{\Lambda}$, American Diabetes Association recommendation; $\diamond$, Oman risk score; , a new risk score in the U.S. B, C, E, and F: O, the New Chinese Diabetes Risk Score; $\bigcirc$, Data from the Epidemiological Study on the Insulin Resistance Syndrome (DESIR); $\square$, Qingdao diabetes risk score; $\mathbf{\square}$, Mauritian Indian risk score. 
large national representative sample and validated in two external populationbased studies. But many questions that were included in other published risk scores such as "delivery of a macrosomic infant" (11), "if steroids are used" (10), or "daily consumption of vegetables, fruits, or berries" (12) were not available in our study questionnaire. To what extent these missing variables will affect the prediction of the risk score is unclear. Moreover, although using the New Chinese Diabetes Risk Score to screen type 2 diabetes may reduce the number of individuals undergoing an OGTT, it will miss people with type 2 diabetes too. The New Chinese Diabetes Risk Score gave a low specificity at the optimal cutoff value. However, the sensitivity and specificity trade off with each other. The choice of a cutoff value depends on the purpose of applying the risk score. As an effective and cheap health promotion tool instead of a diagnostic test, the risk score can reach a large lay population in a short time period, spreading through media, internet, school children, working places, and primary care clinics. As a consequence of the widespread use of the risk score, the public awareness of diabetes and its risk factors that bear on the risk score sheet raised significantly, as shown by our previous work in Qingdao, China (26). From the point of view of public health, a high sensitivity is desired. There were more women than men included in the study. The exploratory population was younger than the two validation populations. These had little influence on the results as shown in the sensitivity analyses. In the current study, the New Chinese Diabetes Risk Score was validated in two Chinese populations living in Qingdao; further validation of the risk score in other parts of China is needed considering the large diversity of the Chinese population. In conclusion, the New Chinese Diabetes Risk Score shows an adequate performance regarding the prediction and detection of type 2 diabetes in China and provides an alternative to the existing simple Chinese diabetes risk score.

Acknowledgments-The study was supported by grants from the Chinese Medical Association Foundation and Chinese Diabetes Society, the National Key Technologies R\&D Program of China (2009BAI80B02), and National High-Tech R\&D Program of China (863 Program 2012AA02A509).
No potential conflicts of interest relevant to this article were reported.

X.Z. designed the study, researched data, and wrote the majority of the manuscript. Q.Q. designed the study, participated in data analysis and interpretation, and reviewed and edited the manuscript. L.J. designed the study, contributed to the discussion, and reviewed and edited the manuscript. F.N. researched data and wrote the manuscript. W.Y., J.W., Z.S., H.T., Q.J., L.L., Q.L., and J.X. collected data, contributed to the discussion, and reviewed and edited the manuscript. W.G. collected data and reviewed and edited the manuscript. Z.P. and J.S. collected data, interpreted the study, contributed to the discussion, and reviewed the manuscript. X.Z. and F.N. are the guarantors of this work and, as such, had full access to all the data in the study and take responsibility for the integrity of the data and the accuracy of the data analysis.

\section{References}

1. Gu D, Reynolds K, Duan X, et al.; InterASIA Collaborative Group. Prevalence of diabetes and impaired fasting glucose in the Chinese adult population: International Collaborative Study of Cardiovascular Disease in Asia (InterASIA). Diabetologia 2003; 46:1190-1198

2. Yang W, Lu J, Weng J, et al.; China National Diabetes and Metabolic Disorders Study Group. Prevalence of diabetes among men and women in China. N Engl J Med 2010;362:1090-1101

3. Consequences of the new diagnostic criteria for diabetes in older men and women. DECODE Study (Diabetes Epidemiology: Collaborative Analysis of Diagnostic Criteria in Europe). Diabetes Care 1999:22:1667-1671

4. Barr EL, Zimmet PZ, Welborn TA, et al. Risk of cardiovascular and all-cause mortality in individuals with diabetes mellitus, impaired fasting glucose, and impaired glucose tolerance: the Australian Diabetes, Obesity, and Lifestyle Study (AusDiab). Circulation 2007;116:151-157

5. Glümer C, Jørgensen T, Borch-Johnsen K; Inter99 study. Prevalences of diabetes and impaired glucose regulation in a Danish population: the Inter99 study. Diabetes Care 2003;26:2335-2340

6. American Diabetes Association. Standards of medical care in diabetes-2011. Diabetes Care 2011;34(Suppl. 1):S11S61

7. Gao WG, Dong YH, Pang ZC, et al. A simple Chinese risk score for undiagnosed diabetes. Diabet Med 2010;27:274281

8. Ruige JB, de Neeling JN, Kostense PJ, Bouter LM, Heine RJ. Performance of an NIDDM screening questionnaire based on symptoms and risk factors. Diabetes Care 1997;20:491-496
9. Baan CA, Ruige JB, Stolk RP, et al. Performance of a predictive model to identify undiagnosed diabetes in a health care setting. Diabetes Care 1999;22:213-219

10. Griffin SJ, Little PS, Hales CN, Kinmonth AL, Wareham NJ. Diabetes risk score: towards earlier detection of type 2 diabetes in general practice. Diabetes Metab Res Rev 2000;16:164-171

11. Rolka DB, Narayan KM, Thompson TJ, et al. Performance of recommended screening tests for undiagnosed diabetes and dysglycemia. Diabetes Care 2001;24:1899_ 1903

12. Lindström J, Tuomilehto J. The diabetes risk score: a practical tool to predict type 2 diabetes risk. Diabetes Care 2003;26: 725-731

13. Glümer C, Carstensen B, Sandbaek A, Lauritzen T, Jørgensen T, Borch-Johnsen $\mathrm{K}$; inter99 study. A Danish diabetes risk score for targeted screening: the Inter99 study. Diabetes Care 2004;27:727-733

14. Balkau B, Lange C, Fezeu L, et al. Predicting diabetes: clinical, biological, and genetic approaches: Data from the Epidemiological Study on the Insulin Resistance Syndrome (DESIR). Diabetes Care 2008;31:2056-2061

15. Aekplakorn W, Bunnag P, Woodward M, et al. A risk score for predicting incident diabetes in the Thai population. Diabetes Care 2006;29:1872-1877

16. Ramachandran A, Snehalatha C, Vijay V, Wareham NJ, Colagiuri S. Derivation and validation of diabetes risk score for urban Asian Indians. Diabetes Res Clin Pract 2005;70:63-70

17. Sun F, Tao Q, Zhan S. An accurate risk score for estimation 5-year risk of type 2 diabetes based on a health screening population in Taiwan. Diabetes Res Clin Pract 2009:85:228-234

18. Bang H, Edwards AM, Bomback AS, et al. Development and validation of a patient self-assessment score for diabetes risk. Ann Intern Med 2009;151:775-783

19. Al-Lawati JA, Tuomilehto J. Diabetes risk score in Oman: a tool to identify prevalent type 2 diabetes among Arabs of the Middle East. Diabetes Res Clin Pract 2007;77: 438-444

20. Gao WG, Qiao Q, Pitkäniemi J, et al. Risk prediction models for the development of diabetes in Mauritian Indians. Diabet Med 2009;26:996-1002

21. Gao WG, Dong YH, Pang ZC, et al.; Qingdao 2006 Diabetes Survey Group. Increasing trend in the prevalence of Type 2 diabetes and pre-diabetes in the Chinese rural and urban population in Qingdao, China. Diabet Med 2009;26: 1220-1227

22. World Health Organization. Definition, Diagnosis and Classification of Diabetes Mellitus and Its Complications: Report of a WHO Consultation. Part 1. Diagnosis and Classification of Diabetes Mellitus. Geneva, 


\section{Risk score for type 2 diabetes}

World Health Org., 1999 (publ. no. 24. Akobeng AK. Understanding diagnostic WHO/NCD/NCS/99.2)

23. Pencina MJ, D'Agostino RB Sr, D'Agostino RB Jr, Vasan RS. Evaluating the added predictive ability of a new marker: from area under the ROC curve to reclassification and beyond. Stat Med 2008; 27:157-172 tests 3: Receiver operating characteristic curves. Acta Paediatr 2007;96:644-647

25. Ta MT, Nguyen KT, Nguyen ND, Campbell LV, Nguyen TV. Identification of undiagnosed type 2 diabetes by systolic blood pressure and waist-to-hip ratio. Diabetologia 2010;53:2139-2146
26. Zhang YL, Gao WG, Pang ZC, et al. Diabetes self-risk assessment questionnaires coupled with a multimedia health promotion campaign are cheap and effective tools to increase public awareness of diabetes in a large Chinese population. Diabet Med 2012;29:e425e429 